\title{
Formation rate of secondary anal fistula after incision and drainage of perianal Sepsis and analysis of risk factors
}

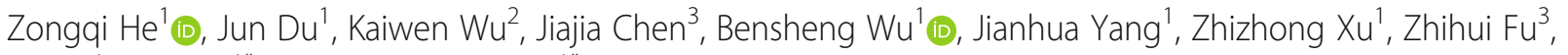
Li Pan ${ }^{1}, K_{\text {Ke Wen }}^{1 *}$ and Xiaopeng Wang ${ }^{1 *}$ (D)

\begin{abstract}
Background: The choice of surgery for perianal sepsis is currently controversial. Some people advocate one-time radical surgery for perianal sepsis, while others advocate incision and drainage. The objective of this study is to observe the formation probability of secondary anal fistula after incision and drainage in patients with perianal sepsis and determine factors that contribute to secondary anal fistula after incision and drainage.

Methods: A retrospective descriptive analysis was conducted in 288 patients with perianal sepsis who were treated with anorectal surgery in the Suzhou Hospital of Traditional Chinese Medicine from January 2016 to June 2018. The patients were followed by telephone, physical examination, and pelvic MRI examination for at least 1 year after surgery.

Results: Three patients were not followed, 98 patients did not receive surgical treatment or one-time radical surgery for perianal sepsis, and 187 patients were ultimately identified for the study. Anal fistula was present in 105 patients, and the rate of formation of secondary anal fistula was $56.15 \%$. There was no statistically significant difference in the fistula formation rate between different types of sepsis $(P>0.05)$. And, in patients with secondary anal fistula, there was no significant correlation between the location of sepsis and the type of secondary anal fistula $(P>0.05)$.

Conclusions: The incidence of secondary anal fistula after incision and drainage of perianal sepsis is $56.15 \%$, which is lower than the incidence found in previous study. Young is a risk factor for secondary anal fistula after incision and drainage of perianal sepsis. There is no significant correlation between the location of sepsis and the type of secondary anal fistula. Simple incision and drainage is a suitable choice for patients with acute perianal sepsis.
\end{abstract}

Keywords: Perianal sepsis, Anal fistula, Secondary, Incision and drainage

\footnotetext{
*Correspondence: wkllcy@163.com; wxpeng2004@163.com

'Department of Anorectal Surgery, Suzhou Hospital of Traditional Chinese Medicine Affiliated to Nanjing University of Chinese Medicine, No. 18, Yangsu Road, Suzhou, Jiangsu, China

Full list of author information is available at the end of the article
}

(c) The Author(s). 2020 Open Access This article is licensed under a Creative Commons Attribution 4.0 International License, which permits use, sharing, adaptation, distribution and reproduction in any medium or format, as long as you give appropriate credit to the original author(s) and the source, provide a link to the Creative Commons licence, and indicate if changes were made. The images or other third party material in this article are included in the article's Creative Commons licence, unless indicated otherwise in a credit line to the material. If material is not included in the article's Creative Commons licence and your intended use is not permitted by statutory regulation or exceeds the permitted use, you will need to obtain permission directly from the copyright holder. To view a copy of this licence, visit http://creativecommons.org/licenses/by/4.0/. The Creative Commons Public Domain Dedication waiver (http://creativecommons.org/publicdomain/zero/1.0/) applies to the data made available in this article, unless otherwise stated in a credit line to the data. 


\section{Background}

Perianal sepsis is a common acute disease in the field of colorectal surgery [1]. In China, the performance of onetime radical surgery for perianal sepsis in patients with this disease is general practice for most surgeons [2-7]. Abscessectomy is typically performed for lower sepsis, and cutting seton is typically placed for upper sepsis [7]. The advantage of this treatment is the reduction in the formation rate of postoperative secondary anal fistula [2-7]; however, at the same time, this treatment causes sphincter function injury and fecal incontinence in some patients [7].

Furthermore, a recent study in the United Kingdom with a large sample size found that the formation rate of secondary anal fistula after incision and drainage of common perianal sepsis was $15.5 \%$, which is far lower than what had been previously thought [8]. However, this reliable formation rate lacks relevant research data in China.

The treatment of perianal sepsis in the anorectal surgery department of the Suzhou Hospital of Traditional Chinese Medicine is as follows: incision and drainage are performed during the acute stage, and fistulectomy or fistulotomy is performed if secondary anal fistula occurs; otherwise, patients continue to receive observation. This study retrospectively descriptively analyzed the incidence of secondary anal fistula after incision and drainage in 187 patients with perianal sepsis treated in the anorectal surgery department of the Suzhou Hospital of Traditional Chinese Medicine, and analyzed the possible risk factors of secondary anal fistula formation after incision and drainage of perianal sepsis.

\section{Methods}

From January 2016 to June 2018, 288 patients with perianal sepsis diagnosed and treated in the anorectal surgery department of the Suzhou Hospital of Traditional Chinese Medicine were obtained by searching the case database. The diagnosis and surgical records were verified by an experienced anorectal surgeon in our hospital. If the patient also had inflammatory bowel disease (IBD), these data were recorded. If perianal sepsis in the patient was caused by foreign body stab wound infection, these data were excluded. At the same time, patients with pilonidal abscesses and diabetes were not included. Except for the cases that needed to be excluded as described above, of the remaining cases, the patients who underwent incision and drainage were included in this study.

During this study, all patients were treated by a standard protocol. All patients were drained by means of a single radial incision under local or spinal anesthesia shortly after arrival on the ward. If the abscess was too large, multiple radial incisions may be made and drained using loose seton. Preoperative imaging, Computed Tomography (CT) or Magnetic Resonance Imaging (MRI), was necessary before making an incision while the surgeon suspected that the abscess was above the levator ani muscle. An antibiotic was given intravenously continuously for 6 days after surgery. Chinese medicine baths (Waike Zuoyu formula) were begun on the first postoperative day and were continued until the wounds were healed.

Follow-up was initiated in July 2019. The follow-up was conducted by an anorectal surgeon who was not involved in the operation from another hospital and a nurse specialist who was experienced with follow-up in our hospital. The postoperative follow-up time of all the included patients was more than one year. Patients were followed by telephone to see if there was any perianal pain or purulent discharge. If none of the symptoms described above occurred or if pelvic MRI indicated no abnormalities, patients were defined as having no anal fistula formation. If the patient had perianal swelling and pain or discharge pus symptoms, and in our hospital or other hospitals, the physical examination and/or pelvic MRI suggested anal fistula, the patient was defined as having anal fistula formation [9]. If the patient had received pelvic CT or MRI examination in our hospital, 2 experienced radiologists and 1 anorectal surgeon read the film independently to identify the fistula location. When there were differences in opinions, 3 people would discuss together and provide final opinions of the images.

\section{Statistical analysis}

All statistical analyses were carried out using $\mathrm{SPSS}^{\oplus}$ version 21.0 (SPSS, Inc., New York, IBM). Continuous variables were analyzed by $t$-tests or nonparametric tests, and classified variables were analyzed by the chi-square test. The correlation was analyzed by binary logistic regression. $P<0.05$ was statistically significant.

\section{Results}

Among the 288 patients with perianal sepsis, 3 patients were not followed (incorrect contact information), and 98 patients did not receive surgery or one-time radical surgery for perianal sepsis. Ultimately, a total of 187 patients were effectively followed and included in this study for statistical analysis. The research flow chart is shown in Fig. 1.

\section{General data analysis of patients with perianal sepsis}

Among the 187 patients with perianal sepsis, 158 were male and 29 were female, and the incidence ratio of males to females was $5.45: 1$. The age at perianal sepsis onset ranged from 10 years to 70 years, with a median age of 35 years. The longest duration was 30 days, the 


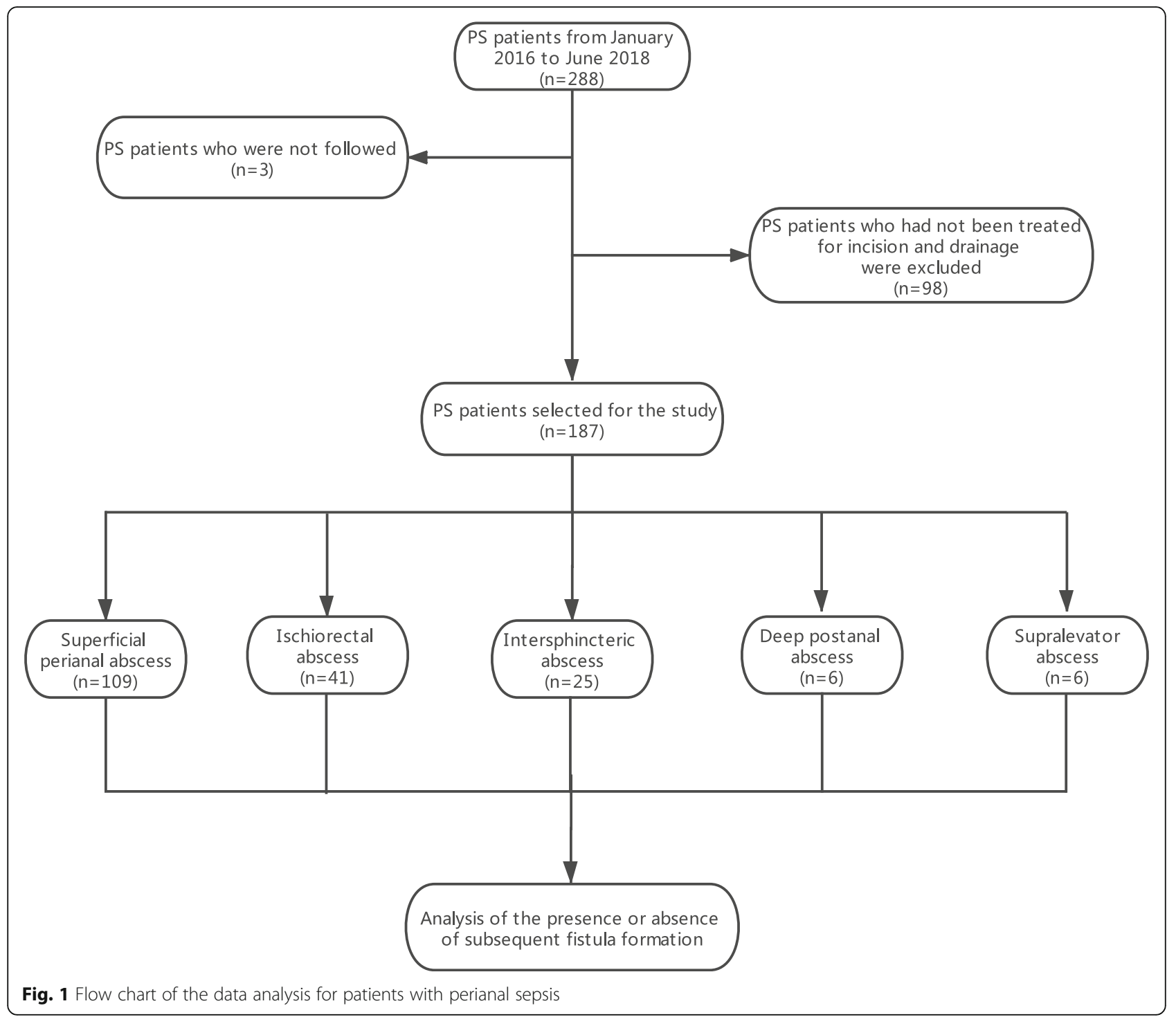

shortest duration was 2 days, and the median duration was 5 days. Among the cases of sepsis, there were 109 cases of superficial perianal sepsis, 6 cases of deep postanal sepsis, 41 cases of ischiorectal sepsis, 25 cases of intersphincteric sepsis and 6 cases of supralevator sepsis. IBD was also present in 8 patients. The follow-up time ranged from 15 months to 44 months, with a median follow-up time of 28 months. General information is shown in Table 1.

\section{Fistula formation after incision and drainage of perianal sepsis}

As shown in Tables 1, 105 of 187 patients (56.15\%) with perianal sepsis who underwent incision and drainage experienced the formation of anal fistula. According to the analysis of the different locations of sepsis, the incidence of fistula in the group with superficial perianal sepsis was 53.21\%, and the incidence of fistula in the group with deep postanal sepsis, ischiorectal sepsis, intersphincteric sepsis, and supralevator sepsis was 33.33, $65.85,56$, and $66.67 \%$, respectively. There was no significant difference in secondary fistula formation among different sepsis locations $(P=0.48,>0.05)$.

\section{Univariate analysis of anal fistula formation}

As shown in Table 1 and Fig. 2, after the analysis of the data of patients with perianal sepsis, in addition to the age at sepsis onset, which was correlated with postoperative anal fistula formation $(P=0.038, P<0.05)$, there was no significant correlation between factors including patient sex $(P=0.908,>0.05)$, sepsis duration $(P=0.638$, $>0.05)$, sepsis location $(P=0.480,>0.05)$, and time of follow-up $(P=0.408,>0.05)$. 
Table 1 Clinical characteristics of the study patients. Values are expressed as the mean \pm standard deviation, number, or median (Q1-Q3)

\begin{tabular}{|c|c|c|c|c|}
\hline & Total & With Fistula & Without Fistula & $P$-value \\
\hline Patients(n) & 187 & 105 & 82 & - \\
\hline Gender(n[\%]) & $187[100]$ & $105[100]$ & $82[100]$ & 0.908 \\
\hline Age (years) & $35(29-47)$ & $34(29-45)$ & $37(31-49)$ & 0.038 \\
\hline Abscess duration (days) & $5(4-7)$ & $5(3.5-7.0)$ & $5(3.8-7.0)$ & 0.638 \\
\hline \multicolumn{5}{|l|}{ Abscess location(n[\%]) } \\
\hline Superficial perianal abscess & $109[58.3]$ & $58[55.2]$ & $51[62.2]$ & \multirow[t]{5}{*}{0.480} \\
\hline Deep postanal abscess & $6[3.2]$ & $2[1.9]$ & $4[4.9]$ & \\
\hline Ischiorectal abscess & $41[21.9]$ & $27[25.7]$ & 14 [17.1] & \\
\hline Intersphincteric abscess & $25[13.4]$ & 14 [13.3] & $11[13.4]$ & \\
\hline Supralevator abscess & $6[3.2]$ & $4[3.8]$ & $2[2.4]$ & \\
\hline With $\mid \mathrm{BD}(\mathrm{n}[\%])$ & $8[4.3]$ & $6[5.7]$ & $2[2.4]$ & 0.272 \\
\hline Time of follow-up (months) & $28(22-35)$ & $27(21.0-34.5)$ & $28(23-36)$ & 0.408 \\
\hline
\end{tabular}

\section{Multivariate analysis of anal fistula formation}

As shown in Table 2, multiple logistic regression analysis was performed to examine whether the location of perianal sepsis was an independent risk factor for anal fistula formation after incision and drainage of perianal sepsis. In the model, sex, age at onset, duration of disease, sepsis location, combined with IBD and follow-up time were included. The results showed that the location of sepsis was not an independent risk factor for secondary anal fistula after incision and drainage of perianal sepsis (odds ratio: 0.929, 95\% confidence interval [CI]: 0.7781.108, $P=0.411$ ). At the same time, sex (odds ratio: 1.147, 95\% confidence interval [CI]: 0.505-2.610, $P=$ 0.743 ), duration (odds ratio: $0.971,95 \%$ confidence interval $[\mathrm{CI}]: 0.913-1.033, P=0.348)$, combined with IBD

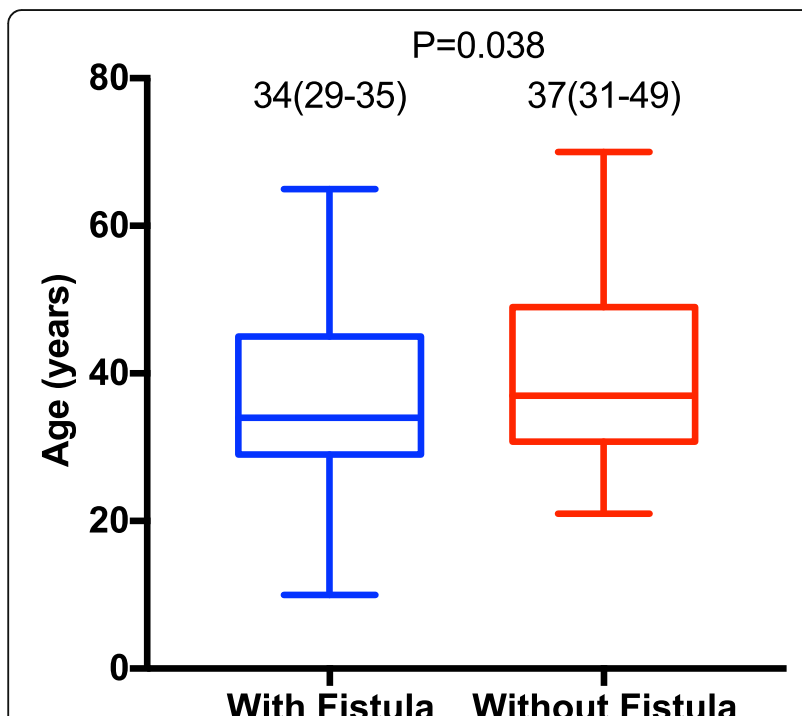

Fig. 2 Relationship between secondary anal fistula after perianal sepsis incision and drainage and age (odds ratio: 1.838, 95\% confidence interval [CI]: 0.5032.603, $P=0.748) 1.837,95 \%$ confidence interval $[\mathrm{CI}]$ : 0.344-9.826, $P=0.476$ ) and follow-up time (odds ratio: 1.009, 95\% confidence interval [CI]: 0.972-1.048, $P=$ 0.632 ) were not significantly associated with the presence of anal fistula after incision and drainage of perianal sepsis. However, age (odds ratio: 1.028, 95\% confidence interval [CI]: 1.002-1.054, $P=0.035$ ) was significantly associated with anal fistula formation after incision and drainage of perianal sepsis.

\section{Relationship between sepsis location and type of anal fistula}

According to further analysis of the data from 105 patients with perianal sepsis who experienced the formation of anal fistula, 55 of them were re-examined or underwent surgery in our hospital, and the type of secondary anal fistula could be determined, while that of the other 50 patients could not be determined. Among the 55 patients, 31 had superficial perianal sepsis: 10 had low intersphincteric fistula, 14 had low trans-sphincteric fistula, 3 had high intersphincteric fistula, 2 had suprasphincteric fistula, and 2 had extrasphincter fistula. In 14

Table 2 Multiple logistic regression analysis of factors associated with secondary anal fistula after perianal sepsis incision and drainage

\begin{tabular}{llll}
\hline & Model & & \\
\cline { 2 - 4 } & OR & $95 \% \mathrm{Cl}$ & $\boldsymbol{P}$-value \\
\hline Sex(n[\%]) & 1.147 & $0.505-2.610$ & 0.743 \\
Age (years) & 1.028 & $1.002-1.054$ & 0.035 \\
Abscess duration (days) & 0.971 & $0.913-1.033$ & 0.348 \\
Abscess location(n[\%]) & 0.929 & $0.778-1.108$ & 0.411 \\
With IBD(n[\%]) & 1.838 & $0.344-9.826$ & 0.476 \\
Time of follow-up (months) & 1.009 & $0.972-1.048$ & 0.632 \\
\hline
\end{tabular}


patients with ischiorectal sepsis, half of them experienced formation of lower trans-sphincter fistula. There were 8 patients with intersphincteric sepsis, $50 \%$ of whom experienced the formation of lower transsphincteric fistula. There were 2 patients with supralevator sepsis, 1 of whom experienced secondary formation of high intersphincteric fistula, and the other experienced the formation of extrasphincter fistula. After analysis, there was no significant correlation between the location of sepsis and the type of secondary anal fistula $(P=0.177,>0.05)$, as shown in Table 3 and Fig. 3.

\section{Discussion}

Perianal sepsis is one of the common diseases in the field of colorectal surgery, and it often causes substantial pain in individuals with the disease $[1,10,11]$. Perianal sepsis often occurs acutely. Once sepsis is formed, it is often difficult to heal on its own, and the condition changes rapidly. If perianal sepsis is not treated, it may cause inflammation and may spread $[1,10,11]$. The disease generally requires emergency surgery. The Italian Society of Colorectal Surgery (ISCR) recommends that perianal sepsis should be drained promptly [10].

However, in China, there are two surgical treatments for perianal sepsis: incision drainage and one-time radical surgery, but there is controversy. Some scholars believe that the traditional incision and drainage method is simple, can promptly improve the clinical symptoms of patients and does not damage sphincter function. However, other scholars believe that the surgical treatment of perianal sepsis should primarily be one-time radical surgery. The latter group believes that perianal sepsis is caused by glandular infection. In these low quality studies, approximately $18.18 \% \sim 66.67 \%$ of patients with perianal sepsis will form anal fistula after incision and drainage in China [2-7]. Mainly, for the treatment of sepsis involving the extent of the lesion, there are potential risks; if the patient also has tuberculosis, Crohn's disease or other diseases, the probability of secondary anal fistula formation is greatly increased [1,8]. Direct resection of low sepsis and the use of a cutting seton for upper sepsis can avoid recrudescence and anal fistula formation [7].

However, the ensuing problem is that some patients suffer from damage to the external sphincter, thus resulting in varying degrees of fecal incontinence $[4,7$, 12]. It is possible that the proportion of patients with anal fistula who undergo radical resection is decreasing; however, do some of these patients actually form anal fistula? At present, there is increasing evidence that the proportion of patients who experience the formation of secondary anal fistula after perianal sepsis is not very high [13-19]. A large sample of data from the United Kingdom found that the incidence of secondary anal fistula after perianal sepsis incision and drainage was $15.5 \%$ [8]. At present, there are no reliable data that support the study of secondary anal fistula in patients with sepsis surgery in China. Our team reviewed and analyzed 288 patients with perianal sepsis. The total fistula formation rate was $56.15 \%$, and there was no statistically significant difference in the fistula formation rate between different types of sepsis. The study by Ghahramani et al. also found location of abscess did not show any association with development of fistula [18]. At the same time, in patients with secondary anal fistula, there was no significant correlation between the location of sepsis and the type of secondary anal fistula.

At present, with the continuous development of imaging technology, research has confirmed that MRI can accurately display the specific location and number of fistula, which provides a favorable reference value for surgery $[10,11,20,21]$. MRI is now the gold standard for the diagnosis of anal fistula and perianal sepsis, but a large number of patients with perianal sepsis often have not been subjected to this test at an earlier time [12]. For high and complex cases of perianal sepsis, if surgeons perform radical surgery without the help of MRI, recurrence is difficult to avoid [22]. Our experience is as follows: If high or complex perianal sepsis is suspected, MRI should be performed before surgery and should be used to determine the spacing and branching involved in the infection.

Table 3 Relationship between perianal sepsis and secondary anal fistula

\begin{tabular}{|c|c|c|c|c|c|c|c|c|c|}
\hline Abscess location & Total & $\begin{array}{l}\text { Superficial } \\
\text { fistula }\end{array}$ & $\begin{array}{l}\text { Low } \\
\text { intersphincteric } \\
\text { fistula }\end{array}$ & $\begin{array}{l}\text { High } \\
\text { intersphincteric } \\
\text { fistula }\end{array}$ & $\begin{array}{l}\text { Low trans- } \\
\text { sphincteric } \\
\text { fistula }\end{array}$ & $\begin{array}{l}\text { High trans- } \\
\text { sphincteric } \\
\text { fistula }\end{array}$ & $\begin{array}{l}\text { Supra- } \\
\text { sphincteric } \\
\text { fistula }\end{array}$ & $\begin{array}{l}\text { Extrasphincteric } \\
\text { fistula }\end{array}$ & $\begin{array}{l}\boldsymbol{P} \text { - } \\
\text { value }\end{array}$ \\
\hline $\begin{array}{l}\text { Superficial } \\
\text { perianal }\end{array}$ & 31 & 0 & 10 & 3 & 14 & 0 & 2 & 2 & 0.177 \\
\hline Deep postanal & 0 & 0 & 0 & 0 & 0 & 0 & 0 & 0 & \\
\hline Ischiorectal & 14 & 0 & 2 & 2 & 7 & 1 & 2 & 0 & \\
\hline Intersphincteric & 8 & 0 & 1 & 2 & 4 & 1 & 0 & 0 & \\
\hline Supralevator & 2 & 0 & 0 & 1 & 0 & 0 & 0 & 1 & \\
\hline Total & 55 & 0 & 13 & 8 & 25 & 2 & 4 & 3 & \\
\hline
\end{tabular}




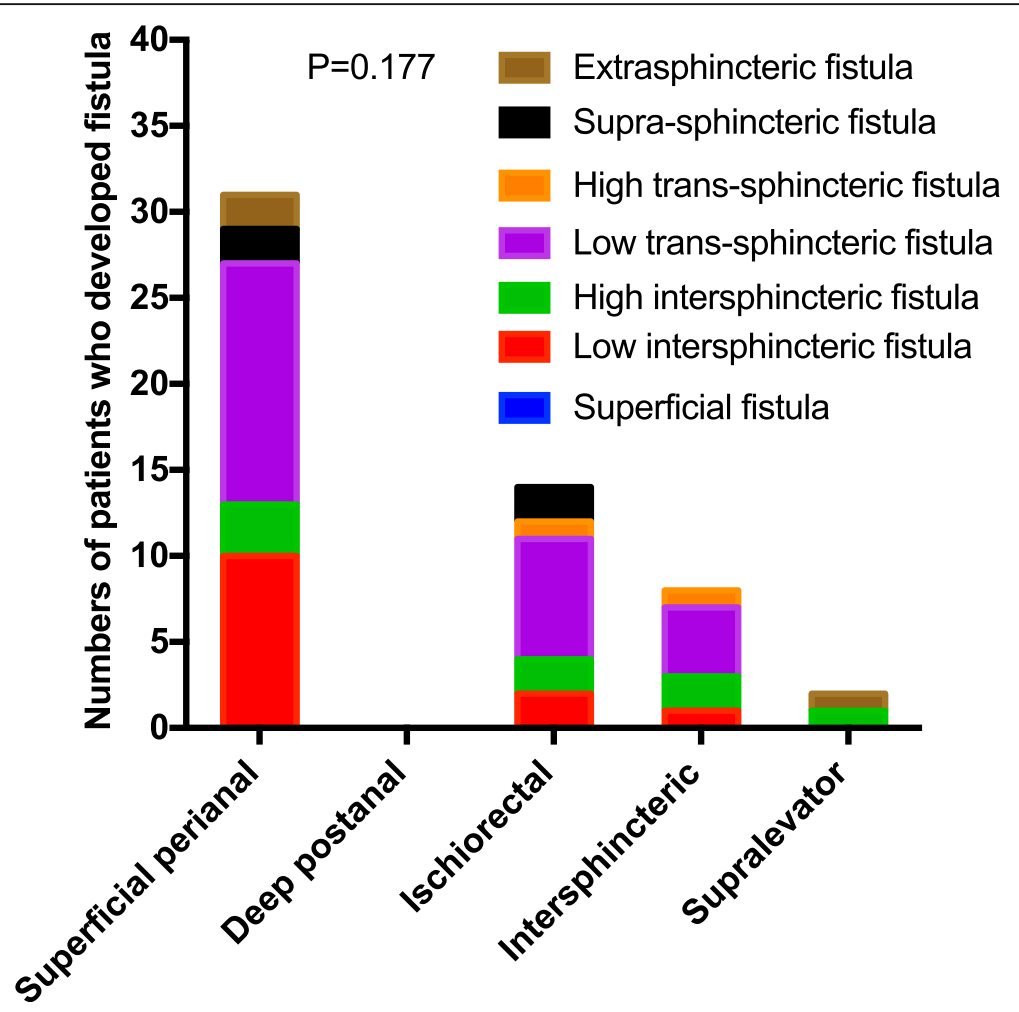

Fig. 3 Relationship between perianal sepsis and secondary anal fistula

In terms of the risk factors for secondary anal fistula, sex, disease duration, sepsis location, and follow-up time were not independent risk factors for secondary anal fistula, and age was an independent risk factor. A similar study also reached the same conclusion, and it found that age younger than 40 years was a high risk factor for chronic anal fistula or perianal sepsis recurrence after incision and drainage [23]. In this study, whether IBD was present was not an independent risk factor for secondary anal fistula, and in another large retrospective analysis, IBD was clearly identified as an independent risk factor for secondary anal fistula formation; thus, the presence of IBD should be given sufficient attention $[1,8]$. In medical practice, we have observed that an increasing number of patients with perianal sepsis combined with IBD are prone to secondary anal fistula. In this study, it may be that the sample size was too small to reflect this difference.

In summary, the proportion of patients with secondary anal fistula after perianal sepsis incision and drainage is not as high as expected, and nearly half of patients will not develop anal fistula. If only used to prevent anal fistula formation or sepsis recurrence, arbitrarily performing radical surgery for perianal sepsis is not only considered excessive surgical treatment but also increases the risk of fecal incontinence and significantly reduces the patient's postoperative quality of life [1,24-26]. Although there is evidence that managing an associated fistula during the acute phase of perianal sepsis can reduce fistula recurrence, there is no enough consensus to support surgeons operating immediate fistula surgery at incision and drainage of perianal sepsis [1].

Therefore, for patients with acute perianal sepsis, it may be necessary to perform incision and drainage to improve the patient's clinical symptoms firstly. Next, if there is secondary anal fistula formation, it is a wise choice to perform fistulectomy or fistulotomy after MRI examination.

This study is limited by its retrospective design and relatively small sample size. If there are more samples, the evidence that secondary anal fistula formation rate after incision and drainage of perianal sepsis may be more adequate.

\section{Conclusions}

Regardless of the cause of the perianal abscess, immediate incision and drainage is standard treatment. About $50 \%$ of patients treated with incision and drainage for perianal sepsis will go on to develop anal fistulas. Young is a risk factor for secondary anal fistula after incision and drainage of perianal sepsis. There was no statistically significant difference in the fistula formation rate between different types of sepsis. For patients with acute perianal sepsis, it may be a suitable choice to perform incision and drainage to improve the patient's clinical symptoms firstly. 


\section{Abbreviation}

IBD: Inflammatory bowel disease; PS: Perianal sepsis

\section{Acknowledgements}

Not applicable.

\section{Ethical approval and consent to participate}

All procedures performed in this study were in accordance with the ethical standards of the institutional research committee and with the 1964 Declaration of Helsinki. Informed consent was obtained from all patients included in this study.

\section{Authors' contributions}

$H Z Q, D J$, and WKW participated in the conception and design of the study. WKW and PL participated in the follow-up of this study. CJJ, FZH, and WXP performed imaging reading. $H Z Q, D J, W B S$ and $X Z Z$ performed the research, analyzed the data, and drafted the manuscript. WK and YJH participated in the revision of the manuscript. All authors have read and approved the final manuscript.

\section{Funding}

Not applicable.

\section{Availability of data and materials}

The data and materials during the current study are available from the first author and the corresponding author on reasonable request.

\section{Consent for publication}

Not applicable.

\section{Competing interests}

Not applicable.

\section{Author details}

${ }^{1}$ Department of Anorectal Surgery, Suzhou Hospital of Traditional Chinese Medicine Affiliated to Nanjing University of Chinese Medicine, No. 18, Yangsu Road, Suzhou, Jiangsu, China. ${ }^{2}$ Department of Anorectal Surgery, Kunshan Fourth Peoples Hospital, No. 21, Zhenbei Road, Kunshan, Jiangsu, China. ${ }^{3}$ Department of Radiology, Suzhou Hospital of Traditional Chinese Medicine Affiliated to Nanjing University of Chinese Medicine, No. 18, Yangsu Road, Suzhou, Jiangsu, China.

Received: 5 January 2020 Accepted: 28 April 2020

Published online: 06 May 2020

\section{References}

1. Sahnan K, Adegbola SO, Tozer PJ, Watfah J, Phillips RK. Perianal abscess. BMJ. 2017;356:1-6.

2. Qin L, Qin X, Liu X, Zheng X, Zhang Y. Clinical evaluation of stage I radical operation for perianal abscess. J Med Forum. 2019:4:88-90.

3. Xie $Y$, Chang J. Retrospective investigation of primary radical operation and simple incision and drainage for perianal abscess patients. Chinese J Mod Oper Surg. 2014;18:413-5.

4. Zhang Y, Bing W. Comparison of curative effect between one-stage radical operation and simple incision and drainage for perianal abscess. Chin J Bases Clin Gen Surg. 2015;22:722-4.

5. Mao $\mathrm{M}$, Zhong $\mathrm{H}$. The effect of surgical treatment of perianal abscess on the efficacy and quality of life of patients. Genomics Appl Biol. 2018:37:2194-9.

6. Li X, Yu Z, Chen K, Wen S. Effects of radical resection and incision drainage in treating patients with perianal abscess. J Color Anal Surg. 2017:23:204-8.

7. Huang J. Comparison of clinical effects of one-time perianal abscess radical resection and simple incision drainage for perianal abscess. Chin J Clin Rational Drug Use. 2019:12:131-2.

8. Sahnan K, Askari A, Adegbola SO, Tozer PJ, Phillips RKS, Hart A, et al. Natural history of anorectal sepsis. Br J Surg. 2017;104:1857-65.

9. Lu D, Lu L, Cao B, Li Y, Cao Y, Li Z, et al. Relationship between body mass index and recurrence/anal fistula formation following initial operation for anorectal abscess. Med Sci Monit. 2019;25:7942-50.

10. Amato A, Bottini C, De Nardi P, Giamundo P, Lauretta A, Realis LuC A, et al. Evaluation and management of perianal abscess and anal fistula : a consensus statement developed by the Italian Society of Colorectal Surgery ( SICCR ). Tech Coloproctol. 2015;19:595-606.

11. Yamana T. Japanese practice guidelines for anal disorders II. Anal fistula. J anus. Rectum Colon. 2018:2:103-9.

12. Seow-Choen F, Nicholls RJ. Anal fistula. Br J Surg. 1992;79:197-205.

13. Ommer A, Herold A, Berg E, Fürst A, Post S, Ruppert R, et al. German S3 guidelines : anal abscess and fistula ( second revised version ). Langenbeck's Arch Surg. 2017:402:191-201.

14. Read DR, Abcarian H. A prospective survey of 474 patients with Anorectal abscess. Dis Colon Rectum. 1979;22:566-8.

15. Jin $\mathrm{H}$, Chen $\mathrm{Y}$, Zhang B. Three-cavity clearance ( TCC ) can decrease the fistula rate after drainage of a perianal abscess : a case - control study. Gastroenterol Rep. 2018;6:221-4.

16. Vasilevsky C, Gordon PH. The incidence of recurrent abscesses or fistula-inano following Anorectal suppuration. Dis Colon Rectum. 1984:27:126-30.

17. Gong Z, Han M, Wu Y, Huang X, Xu W-J, Lv Z. Treatment of first-time perianal abscess in childhood, balance recurrence and fistula formation rate with medical intervention. Eur J Pediatr Surg. 2017;28:373-7.

18. Ghahramani L, Minaie MR, Arasteh P, Hosseini SV, Izadpanah A, Bananzadeh AM, et al. Antibiotic therapy for prevention of fistula in-ano after incision and drainage of simple perianal abscess: a randomized single blind clinical trial. Surgery. 2017;162:1017-25.

19. Mocanu V, Dang JT, Ladak F, Tian C, Wang H, Birch DW, et al. Antibiotic use in prevention of anal fistulas following incision and drainage of anorectal abscesses: a systematic review and meta-analysis. Am J Surg. 2019:217:910-7.

20. Konan A, Onur MR, Özmen MN. The contribution of preoperative MRI to the surgical management of anal fistulas. Diagn Interv Radiol. 2018;24:321-7.

21. Garg P, Singh P, Kaur B. Magnetic resonance imaging (MRI): operative findings correlation in 229 fistula-in-Ano patients. World J Surg. 2017:41: 1618-24.

22. Garg P. Comparison of preoperative and postoperative MRI after fistula-inAno surgery: lessons learnt from an audit of $1323 \mathrm{MRI}$ at a single Centre. World J Surg. 2019;43:1612-22.

23. Hamadani A, Haigh PI, Liu ILA, Abbas MA. Who is at risk for developing chronic anal fistula or recurrent anal sepsis after initial perianal abscess? Dis Colon Rectum. 2009:52:217-21.

24. Malik Al, Nelson R, Tou S. Incision and drainage of perianal abscess with or without treatment of anal fistula. Cochrane Database Syst Rev. 2010.

25. Oliver I, Lacueva F, Pérez Vicente F, Arroyo A, Ferrer R, Cansado P, et al. Randomized clinical trial comparing simple drainage of anorectal abscess with and without fistula track treatment. Int J Color Dis. 2003;18:107-10.

26. Pigot F. Treatment of anal fistula and abscess. J Visc Surg. 2015;152:S23-9.

\section{Publisher's Note}

Springer Nature remains neutral with regard to jurisdictional claims in published maps and institutional affiliations.

Ready to submit your research? Choose BMC and benefit from:

- fast, convenient online submission

- thorough peer review by experienced researchers in your field

- rapid publication on acceptance

- support for research data, including large and complex data types

- gold Open Access which fosters wider collaboration and increased citations

- maximum visibility for your research: over $100 \mathrm{M}$ website views per year

At BMC, research is always in progress.

Learn more biomedcentral.com/submission 